\title{
In Search of the Identity of the Cerebellar Climbing Fiber Transmitter: Immunocytochemical Studies in Rats
}

\author{
Nianhui Zhang and Ole P. Ottersen
}

\begin{abstract}
Quantitative immunogold cytochemistry at the electron microscopic level was used to assess the endogenous contents of glutamate, aspartate, homocysteic acid, and glutamine (a precursor of glutamate) in the cerebellar climbing fiber terminals. Of the three excitatory amino acids, only glutamate appeared to be enriched in these terminals. The climbing fiber terminals also displayed immunoreactivity for glutamine. The level of aspartate immunoreactivity was far higher in the nerve cell bodies in the inferior olive than in their terminals in the cerebellar cortex. Homocysteic acid immunolabelling was concentrated in glial cells including the Golgi epithelial cells in the Purkinje cell layer. Our immunocytochemical data indicate that glutamate is a more likely climbing fiber transmitter than aspartate and homocysteic acid.
\end{abstract}

RÉSUMÉ: À la recherche du neurotransmetteur des fibres grimpantes du cervelet: études immunocytochimiques chez le rat. Nous avons utilisé une technique immunohistochimique par marquage à l'or quantifié par microscopie électronique pour évaluer le contenu endogène en glutamate, aspartate, acide homocystéique et glutamine (un précurseur du glutamate) des terminaisons des fibres grimpantes du cervelet. Parmi les trois acides aminés excitateurs, seul le glutamate semblait être plus abondant dans ces terminaisons. Les terminaisons des fibres grimpantes présentaient également une immunoréactivité pour la glutamine. Le niveau d'immunoréactivité de l'aspartate était beaucoup plus élevé dans les corps cellulaires des neurones de l'olive inférieure que dans leurs terminaisons dans le cortex cérébelleux. Le marquage immunologique de l'acide homocystéique était concentré dans les cellules gliales, incluant les cellules épithéliales du Golgi dans la couche moyenne de l'écorce cérébelleuse. Nos données immunohistochimiques indiquent qu'il est plus plausible que ce soit le glutamate plutôt que l'aspartate ou l'acide homocystéique qui soit le neurotransmetteur des fibres grimpantes.

Can. J. Neurol. Sci. 1993; 20 (Suppl. 3): S36-S42

Almost 20 years ago, Young et al.' were able to show that virus-induced destruction of cerebellar granule cells in hamsters led to a selective decrease in the level of endogenous glutamate and glutamate/aspartate uptake in the cerebellar cortex. In the years that have elapsed since this pioneering study, evidence has continued to accumulate that glutamate is the transmitter of the granule cell axons (parallel fibers). ${ }^{2 \cdot 4}$ Recent investigations indicate that this amino acid is also one of several neurotransmitters/neuromodulators in the mossy fiber system. ${ }^{4-7}$

The identification of the transmitter(s) of the third major excitatory fiber system in the cerebellum - the climbing fibers has proved to be a difficult task. There is general agreement that the fast signalling in the latter system is mediated via excitatory amino acid receptors, most probably of the non-NMDA (Nmethyl-D-aspartate) type, ${ }^{8.10}$ but the identity of the endogenous agonist of these receptors has been a matter of dispute.

L-Aspartate was proposed as a likely candidate following the observations that D-aspartate is taken up and transported retrogradely by the climbing fibers," and that lesions of the inferior olive with 3-acetylpyridine cause a reduction in the calcium- dependent release of endogenous L-aspartate from cerebellar slices. ${ }^{12.13}$ The latter effect was confined to the hemispheres; no change was seen in the vermis. ${ }^{13}$

These studies did not, however, rule out a possible involvement of glutamate. It is well known that the high affinity uptake system is unable to distinguish between glutamate and aspartate. ${ }^{14}$ Further, the 3 -acetylpyridine treatment led to a reduced release of glutamate as well as aspartate, although the effect on glutamate release failed to reach significance ${ }^{12}$ or was significant only in the vermis. ${ }^{13}$ The authors of the latter reports have been careful to point out that a lesion-induced effect on glutamate release from the climbing fibers could have been easily masked by the massive glutamate efflux from the parallel fiber system. Glutamate has consequently been left in limbo as far as its role as climbing fiber transmitter is concerned.

Glutamate and aspartate have long standing as the preeminent excitatory transmitter candidates in the CNS. ${ }^{14}$ However, it has been known since the early work of Curtis and Watkins ${ }^{15}$ that some sulfur-containing amino acids have excitatory properties similar to those of glutamate and aspartate. The interest in 
sulfur-containing amino acids was revived following the observation that several of them, including homocysteic acid, could be released in a calcium-dependent manner from brain tissue.$^{16-17}$ Indeed, homocysteic acid was claimed to be the most likely endogenous agonist of the NMDA receptor in certain cortical fiber systems. ${ }^{18,19}$ Studies in the cerebellum showed that the release of homocysteic acid could be abolished after elimination of the climbing fibers by 3 -acetylpyridine. ${ }^{13}$ This effect was observed in both hemispheres and vermis, and was initially taken as evidence for a transmitter role of homocysteic acid in the climbing fiber system. Alternative interpretations were offered in subsequent reports from the same group (see Discussion and refs. ${ }^{20}$ and ${ }^{21}$ ).

Immunocytochemistry should be well suited for resolving whether the fast chemical signalling of the climbing fibers is mediated by aspartate, glutamate, and/or homocysteic acid. We have raised antisera to each of these amino acids and to glutamine, which is considered to be a major precursor of transmitter glutamate. ${ }^{14}$ In the following we will briefly describe the labelling pattern that these antisera produce in the rat cerebellum, with particular reference to the climbing fibers.

\section{METHODS AND MATERIALS}

Male Wistar rats were perfused through the heart with a mixture of $2.5 \%$ glutaraldehyde and $1 \%$ paraformaldehyde. Sagittal and transverse, hand-cut slices of the cerebellum were treated with $\mathrm{OsO}_{4}$, dehydrated, and embedded in Durcupan. Semithin sections $(0.5 \mu \mathrm{m})$ were immersed in sodium ethanolate (to remove resin), and then subjected to post-embedding, peroxidase-antiperoxidase immunocytochemistry. ${ }^{22}$ The homocysteic acid antiserum (code no. 553; ref. ${ }^{23}$ ) was diluted 1:100 and preabsorbed with glutaraldehyde $(\mathrm{G})$ complexes of glutamine (100 $\mu \mathrm{M})$ and of glutamate and taurine $(50 \mu \mathrm{M}$ each).

Ultrathin sections were processed according to a postembedding, immunogold procedure based on that of Somogyi et al. ${ }^{4}$ The following rabbit antisera were used (dilution and concentration of $\mathrm{G}$ complexes added are given for each antiserum): 1 , glu-

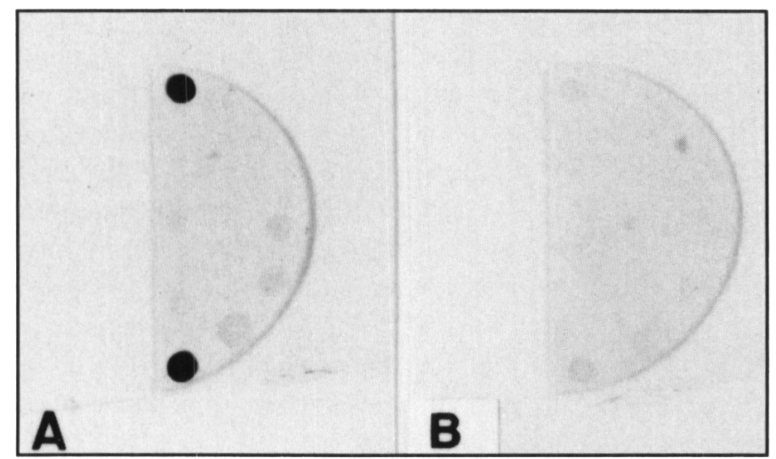

tamate $03,{ }^{5} 1: 300,150 \mu \mathrm{M}$ glutamine-G and $100 \mu \mathrm{M}$ aspartate$\mathrm{G} ; 2$, glutamine $34,24.251: 600,60 \mu \mathrm{M}$ aspartate-G; 3, aspartate $18,{ }^{26.27} 1: 50,50 \mu \mathrm{M}$ glutamate-G; 4, aspartate 435, 1:100, 60 $\mu \mathrm{M}$ glutamate-G, $10 \mu \mathrm{M}$ taurine-G, and $100 \mu \mathrm{M}$ GABA-G; 5, homocysteic acid $553,{ }^{23} 1: 50,30 \mu \mathrm{M} \beta$-alanine-G, $200 \mu \mathrm{M}$ glutamine-G, $50 \mu \mathrm{M}$ glutamate-G, and $50 \mu \mathrm{M}$ taurine-G. Bound antibodies were visualized by use of sheep anti-rabbit IgG coupled to colloidal gold particles (Janssen).

The ultrathin sections were labelled with a single antiserum (Figure 2B) or with two different antisera, using two different gold particle sizes (Figures 2A, 5B). The double-labelling procedure was identical to that used previously in our laboratory ${ }^{28.29}$ and was based on the protocol of Wang and Larsson. ${ }^{30}$ It included two sequential incubations with an intervening formaldehyde vapour treatment. The taurine antiserum (code no. 286) that was used for homocysteic acid/taurine double labelling (Figure 5B) was diluted 1:900 and preabsorbed with $50 \mu \mathrm{M} \beta$ alanine-G.

All antisera have been subjected to extensive specificity testing, using two different model systems. Initial screening was performed by immunoincubation of cellulose nitrate/acetate discs carrying a series of amino acid conjugates. ${ }^{26}$ One example, based on aspartate antiserum 435, is shown in Figure 1. This antiserum reacts selectively with L-aspartate, and shows no

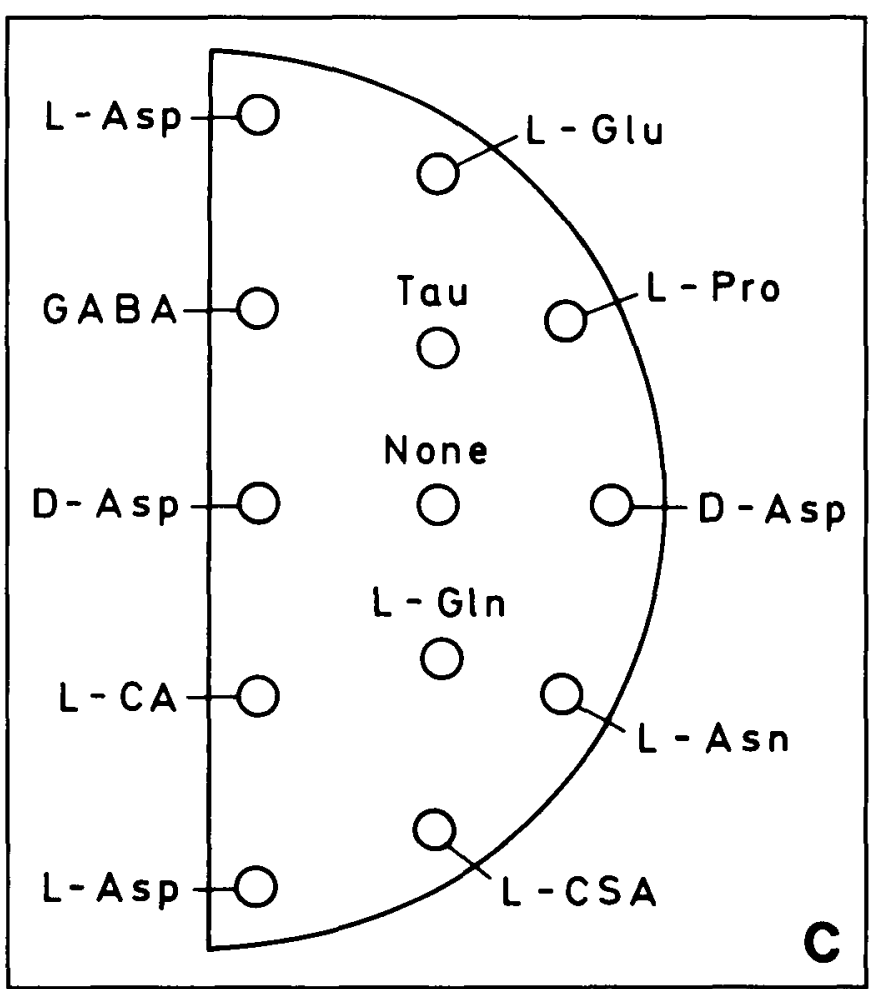

Figure I-Characterization of L-aspartate antiserum no. 435 by "spot-test" (peroxidase-antiperoxidase procedure). Amino acids (code in C) were coupled to a thoroughly dialyzed extract of brain macromolecules, using the same mixture of glutaraldehyde and formaldehyde that was used for tissue fixation. The conjugates were spotted onto cellulose nitratelacetate discs. A: The antiserum (diluted 1:10 000 and preabsorbed with glutaraldehyde complexes of glutamate and asparagine; $200 \mu \mathrm{M}$ of each) produced selective staining of the respective amino acid conjugate (L-Asp), and did not react with the stereoisomer D-Asp. B: Same antibody preparation as in A, but with addition of L-aspartate-aldehyde-brain protein conjugates $(300 \mu \mathrm{M})$. Note complete blocking of immunostaining. C: Code for A and B. The amino acids that were tested included those that show close structural analogy with $L$-aspartate. The amino acids were (listed from top of filter in the clockwise direction, followed by the central spots): $L$-aspartate, $L$-glutamate, $L$-proline, $D$-aspartate, L-asparagine, $L$-cysteine sulphinic acid, L-aspartate, $L$-cysteic acid, D-aspartate, gammaaminobutyrate, taurine, and L-glutamine. "None" represents aldehyde-treated brain macromolecules (no amino acid added). This "spot-test" was employed for screening of all antisera used in the present report, and a highly selective immunostaining was observed in each case. 
affinity to close structural analogues such as cysteine sulphinic acid (L-CSA). The latter amino acid is identical to $\mathrm{L}$-aspartate except that it contains a $\mathrm{SO}_{2} \mathrm{H}$ group instead of a $\mathrm{COOH}$ group. The aspartate antiserum is specific for the L-isomer of aspartate (Figure 1). The second model system was based on amino acid conjugates as above, but instead of spotting them onto discs they were embedded in Durcupan and assembled in a sandwich. ${ }^{29}$ Sections through the sandwich could then be incubated together with the tissue sections, allowing identical conditions for testing and immunocytochemistry (amino acid conju-

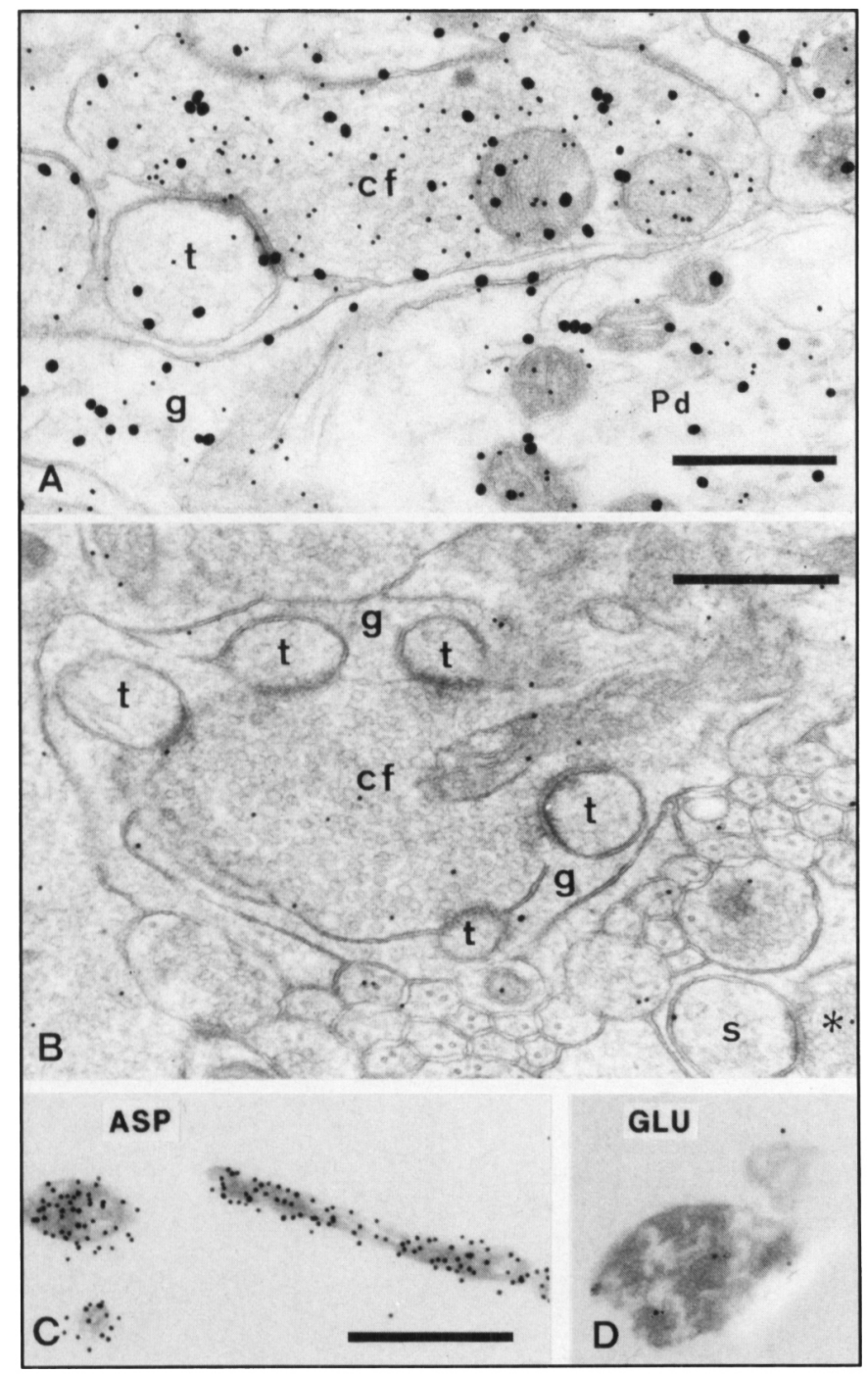

Figure 2 - Postembedding immunogold labelling with a glutamine antiserum followed by a glutamate antiserum $(A)$, and with an aspartate antiserum (no. $435 ; B$-D). Glutamate-like immunoreactivity (small gold particles in $A$ ) is concentrated in the climbing fiber terminal $(c f)$ while glutamine-like immunoreactivity (large particles) is highest in glial profiles (g). Pd, dendrite, and $t$, dendritic thorn, of a Purkinje cell. L-Aspartate immunoreactivity is weak in climbing fiber terminals $(B)$ but strong labelling is seen of $L \cdot a$ spartate conjugates $(C)$. No accumulation of gold particles occurs over the glutamate conjugates $(D)$, attesting to the high selectivity of the aspartate antiserum. The conjugates shown in $C$ and $D$ are two out of a series of different conjugates that are incorporated in test sections and incubated together with the tissue sections (see Methods and Materials). Asterisk in B indicates a parallel fiber terminal establishing contact with a dendritic spine (s). Scale bars: $0.5 \mu \mathrm{m}$. gates from such a sandwich are shown in Figure 2C, D). Using these two model systems, a high selectivity has been demonstrated for all of the antisera that were used in the present study: glutamate $03,{ }^{5}$ glutamine $34,{ }^{24,25}$ aspartate $18,{ }^{26.27}$ aspartate 435 (Figure 1), and homocysteic acid 553. ${ }^{23}$

The gold particle densities over different cell profiles were quantified by means of a purpose-made computer programme. ${ }^{31}$

\section{RESULTS}

The climbing fiber terminals were covered with numerous gold particles signalling glutamate-like immunoreactivity (small particles in Figure 2A). The particle density was similar to that over terminals of parallel and mossy fibers, and substantially higher than that over Purkinje cell somata and dendrites, basket cell terminals, and astrocytes (Figures 2A, 3A). (In a previous study, ${ }^{27}$ the climbing fibers were found to be somewhat less intensely labelled than the parallel fibers.) Separate experiments showed that the level of glutamate immunoreactivity in climbing fiber terminals was about the same as that in the parent cell bodies of the inferior olive (Figure 4B).

Glutamine immunoreactivity (signalled by large gold particles in Figure 2A) was present in climbing fibers, but the average level of immunoreactivity in those was lower than that in other structures including Purkinje cells and glial processes (Figures 2A, 3B). The latter type of profile was the most strongly glutamine immunolabelled element in the cerebellar cortex.

The double labelling procedure allowed us to calculate the ratio between the gold particle densities signalling glutamate and glutamine, respectively. This "glutamate/glutamine ratio" is assumed to reflect the rate at which glutamine is converted into glutamate. ${ }^{29}$ The ratios were significantly higher in the terminals of the major excitatory fiber systems than in other tissue compartments (Figure 3 ). The parallel fiber terminals in the outer part of the molecular layer displayed particularly high values due to their weak glutamine immunolabelling.

Incubations with the aspartate antiserum produced a very low particle density over the climbing fiber terminals (Figure $2 \mathrm{~B}$ ), in the hemispheres as well as in vermis. Indeed, their labelling intensity was not significantly different from the average labelling intensity in the cerebellar cortex and only slightly above background level (over empty resin). This negative result was not due to technical problems since model conjugates of aspartate that had been incubated together with the tissue sections and thus under the same conditions as those, showed strong labelling (Figure 2C). Noteworthy immunolabelling also occurred in somata of inferior olivary neurons (Figure 4A), suggesting that the concentration of aspartate decreases when moving along the axons from the cell bodies towards the climbing fiber terminals. As mentioned above, a similar gradient was not found in the case of glutamate (Figure 4B). The sections from the cerebellum and inferior olive were from the same animals and had been incubated in the same drops of immunoreagents in order to permit direct comparison.

Like the aspartate antiserum, the antiserum to homocysteic acid failed to produce significant labelling of climbing fiber terminals. This was true both at the light microscopic (Figure 5A) and electron microscopic levels (not shown). Most of the immunoreactivity was localized in glial elements, including Golgi epithelial cells in the Purkinje cell layer, and astrocytes in 
the granule cell layer (Figure 5A). In the latter layer, distinct labelling was observed in delicate processes outlining granule cell bodies and sometimes contacting blood vessels. The glial nature of the immunolabelled processes in the molecular and granule cell layer was confirmed in the electron microscope (Figure 5B).
Sections double labelled for homocysteic acid and taurine revealed non-overlapping distributions of these two sulfur-containing amino acids (Figure 5B). Taurine immunoreactivity was concentrated in cell bodies and processes of Purkinje cells, as described previously. ${ }^{32}$

\begin{tabular}{|c|c|c|c|c|}
\hline & Glu & $G \ln$ & & \\
\hline & A & $\mathrm{B}$ & & $\frac{G l u}{G l n}$ \\
\hline Paral.fib. Mo & 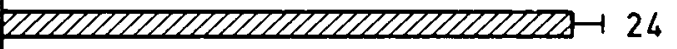 & EDAH 24 & & 10.4 \\
\hline Mossy fib. & 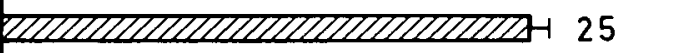 & 25 & & 4.2 \\
\hline Climb.fib. & 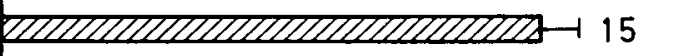 & एस्थयक- 15 & & 4.9 \\
\hline Gran. somata & 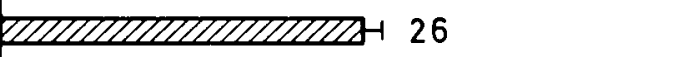 & स्सयस्म- 26 & & 2.2 \\
\hline Basket term & 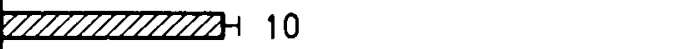 & स20202-10 & & 1.5 \\
\hline Purk. somata & 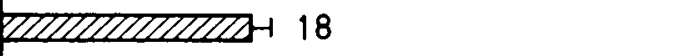 & स्थस्थयक- 18 & & 1.2 \\
\hline Astrocytes & ZZZZZA- 23 & ZZZZZZZZZZZS- 2 & & 0.5 \\
\hline & 1 & 1 & 1 & \\
\hline & 20 & 40 & 60 & \\
\hline & Gold $p$ & es $/ \mu m^{2}$ & & \\
\hline
\end{tabular}

Figure 3 - Quantitation of immunolabelling for glutamate $(A)$ and glutamine (B), based on double-labelled preparations similar to that shown in Figure 2A. "Astrocytes" include Golgi epithelial cells, and astrocytes in the granule cell layer. All profiles were sampled in a random manner from the entire radial extent of the respective layers. An exception was made for the parallel fiber terminals, which were also sampled in a random manner but only from the outer part (Mo) of the molecular layer: No attempt was made to differentiate berween different subsets of mossy fiber terminals (but see ref. ${ }^{5}$ ). S.E.M. and number of observations (profiles) are indicated. The ratio between the respective gold particle densities was calculated for each type of profile (right column). Based on data from ref. ${ }^{29}$.

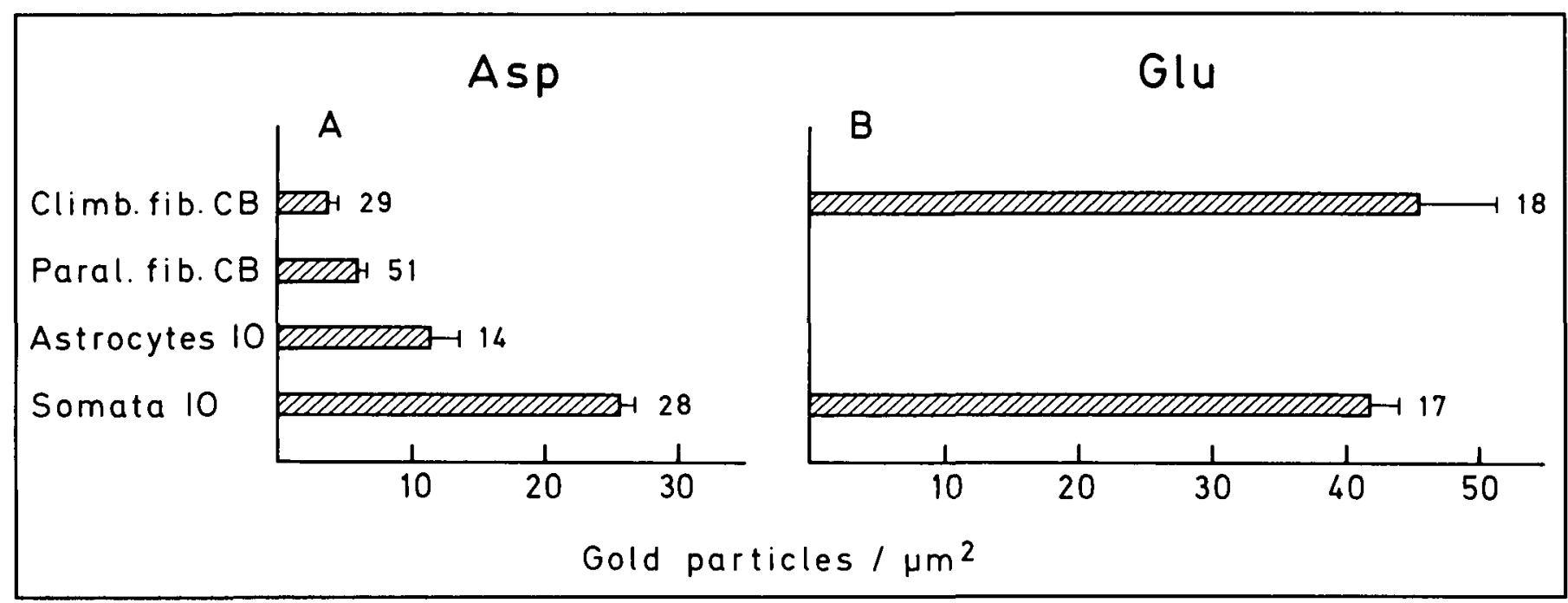

Figure 4-Quantitation of immunolabelling for aspartate $(A)$ and glutamate $(B)$ in the inferior olive (IO) and cerebellar cortex (CB). "Somata" refer to cell bodies of olivocerebellar neurons. Based on single-labelled immunogold preparations. S.E.M. and number of observations are indicated. Based on data from ref. ${ }^{27}$. 


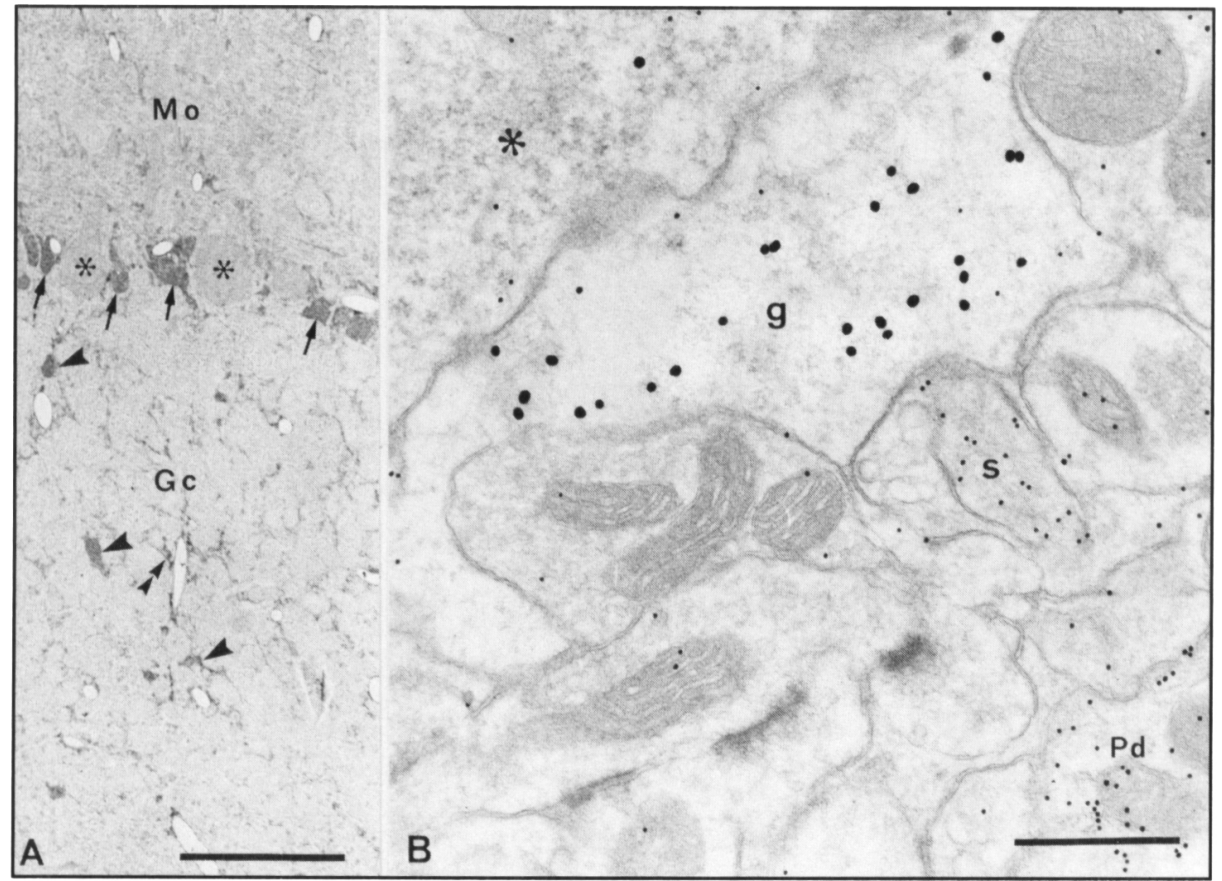

Figure 5 - Light $(A)$ and electron microscopic ( $B$, large gold particles) immunolabelling with a homocysteic acid antiserum. Immunoreactivity occurs in Golgi epithelial cells (arrows). astrocytes (arrowheads), and in glial processes, some of which approach blood vessels (double arrowhead). The labelling of glial processes is confirmed electron microscopically ( $g$ in $B$ ). The small particles in B signal caurine immunoreactivity, which is concentrated in Purkinje cell dendrites $(P d)$ and spines (s). Mo. molecular layer; Gc, gramule cell layer; asterisks in A, Purkinje cell bodies; asterisk in B. stellate or basket cell body. Scale bars: $A, 50 \mu \mathrm{m} ; B, 0.5 \mu \mathrm{m}$.

\section{DISCUSSION}

The weak aspartate immunolabelling of climbing fiber terminals is difficult to reconcile with a transmitter role of this amino acid. The intracellular gradient of aspartate disclosed in the present study, with the highest concentration in the cell body, rather suggests that aspartate serves metabolic roles in the olivocerebellar fiber system. If this is correct, it needs to be explained why climbing fiber deprivation caused a reduction in endogenous aspartate release. ${ }^{12.13}$ Several alternative explanations have been discussed previously. ${ }^{27.33}$ Suffice it to mention that the release experiments were conducted in vitro while the present observations were based on material that had been fixed by rapid in vivo perfusion. It is conceivable that in vitro conditions may allow endogenous aspartate to accumulate in the climbing fibers. This may occur due to uptake of aspartate that has been leaked into the medium from other cell compartments, or due to a conversion of glutamate to aspartate (this conversion is catalyzed by aspartate aminotransferase, which is an ubiquitous enzyme in brain tissue). ${ }^{14}$ Indeed, in vitro experiments performed in our own laboratory suggest that aspartate immunoreactivity does appear in climbing fibers under suitable incubation conditions. ${ }^{33}$

One must also consider the possibility that a transmitter pool of aspartate might have escaped detection because of insufficient sensitivity of our immunocytochemical procedure. This is unlikely because the aspartate antiserum produces very strong labelling of aspartate conjugates (Figure 2C). Such model conjugates were prepared by coupling the amino acid to an extract of rat brain macromolecules by means of the fixative used for perfusion. The complexes thus formed should mimic the antigens that the antibodies encounter in the tissue. ${ }^{34}$ The concentration of fixed aspartate in the model conjugate shown in Figure $2 \mathrm{C}$ is high (about $150 \mathrm{mM}$ ) compared to the average tissue level of aspartate $(2-3 \mathrm{mM})$. However, our glutamate antiserum $03^{29}$ and L-aspartate antiserum 435 (N. Zhang and O.P. Ottersen, unpublished observations) have been shown to detect antigen concentrations as low as $0.2 \mathrm{mM}$ under incubation conditions similar to those used here. L-Aspartate is retained as efficiently as glutamate by fixation with glutaraldehyde. ${ }^{34}$

Our finding of a very low level of homocysteic acid immunoreactivity in climbing fiber terminals is in line with recent reports of Cuénod et al. ${ }^{20}$ and Streit et al. ${ }^{21}$ Using antisera produced independently of ours, they were able to demonstrate distinctly immunolabelled processes in semithin sections of the molecular layer. Neighbour ultrathin sections were examined electron microscopically and revealed that the labelled processes were not climbing fibers as first thought, but glial profiles. We have presently confirmed this by direct immunolabelling of ultrathin sections (also see ref. ${ }^{23}$ ). Streit et al. ${ }^{21}$ have proposed that glial cells may release homocysteic acid in response to stimulation by the climbing fiber transmitter. Such a mechanism is without precedence but would explain why the homocysteic acid release depends on the integrity of the climbing fiber system. ${ }^{13}$

We are thus left with glutamate as the only excitatory amino acid shown by immunocytochemistry to be enriched in climbing fiber terminals. As mentioned in the Introduction, the release experiments that have been performed so far do not exclude the possibility that glutamate is a climbing fiber transmitter. One 
problem in release studies is that the climbing fibers are exceedingly few compared to the parallel fibers. Any glutamate release from the former fibers may therefore be obscured by the glutamate efflux from the latter.

The immunocytochemical data favouring glutamate as a transmitter in climbing fibers are not as clear as the corresponding data for the parallel fibers ${ }^{4.29}$ and for well-established excitatory fibers (Schaffer collaterals and mossy fibers) in the hippocampus. ${ }^{35}$ Each of these fiber systems displays an enrichment of glutamate immunoreactivity in the nerve terminals relative to the parent cell bodies. No evidence was obtained for such an intracellular glutamate gradient in olivocerebellar neurons (the difference indicated in Figure $4 \mathrm{~B}$ is not statistically significant). It is also clear that the glutamate/glutamine ratio (which is assumed to reflect the rate of glutamate formation from glutamine; see ref. ${ }^{29}$ ) was considerably lower in climbing fiber terminals than in terminals of parallel fibers, at least when compared with parallel fibers in the outer part of the molecular layer. However, the ratio in climbing fiber terminals was not significantly different from that in mossy fiber terminals (present report and ref. ${ }^{29}$ ).

\section{Conclusion}

Judged from the present immunocytochemical data, glutamate emerges as the most likely excitatory amino acid transmitter in the climbing fibers. This would be consistent with recent pharmacological analyses. ${ }^{8}$ The biochemical evidence suggesting transmitter roles of homocysteic acid and aspartate does not receive immunocytochemical support. It should finally be noted that climbing fibers are equipped with several neuroactive compounds that do not belong to the family of excitatory amino acids. At least one of these compounds (corticotropin releasing factor) has been shown to modulate the effect of excitatory amino acids on the Purkinje cells. ${ }^{36}$

\section{REFERENCES}

1. Young $A B$, Oster-Granite ML, Herndon RM, et al. Glutamic acid: selective depletion by viral-induced granule cell loss in hamster cerebellum. Brain Res 1974; 73: 1-13.

2. Sandoval ME, Cotman $\mathrm{CW}$. Evaluation of glutamate as neurotransmitter of cerebellar parallel fibers. Neuroscience 1978; 3: 199-206.

3. Stone TW. Glutamate as the neurotransmitter of cerebellar granule cells in the rat: electrophysiological evidence. $\mathrm{Br} J$ Pharmacol 1979; 66: 291-296.

4. Somogyi P, Halasy K, Somogyi J, et al. Quantification of immunogold labelling reveals enrichment of glutamate in mossy and parallel fibre terminals in cat cerebellum. Neuroscience 1986; 19: 1045-1050.

5. Ji Z, Aas J-E, Laake J, et al. An electron microscopic immunogold analysis of glutamate and glutamine in terminals of rat spinocerebellar fibers. J Comp Neurol 1991; 307: 296-310.

6. Liu C-j, Grandes P, Matute C, et al. Glutamate-like immunoreactivity revealed in rat olfactory bulb, hippocampus and cerebellum by monoclonal antibody and sensitive staining method. Histochemistry 1989; 90: 427.445.

7. Garthwaite J, Brodbelt AR. Glutamate as the principal mossy fiber transmitter in rat cerebellum: pharmacological evidence. Eur J Neurosci 1990; 2: 177-180.

8. Hirano T. Synaptic transmission between rat inferior olivary neurons and cerebellar Purkinje cells in culture. J Neurophysiol 1990; 63: 181-189.

9. Konnerth A, Llano I, Armstrong CM. Synaptic currents in cerebellar Purkinje cells. Proc Natl Acad Sci USA 1990; 87: 2662-2665.
10. Perkel DJ, Hestrin S, Sah P, et al. Excitatory synaptic currents in Purkinje cells. Proc Roy Soc Lond B: 1990; 241: 116-121.

11. Wiklund L, Toggenburger G, Cuénod M. Aspartate: possible neurotransmitter in cerebellar climbing fibers. Science 1982; $216: 78-$ 80.

12. Toggenburger G, Wiklund L, Henke H, et al. Release of endogenous and accumulated exogenous amino acids from slices of normal and climbing fiber-deprived rat cerebellar slices. J Neurochem 1983; 41: 1606-1613.

13. Vollenweider FX, Cuénod M, Do KQ. Effect of climbing fiber deprivation on release of endogenous aspartate, glutamate, and homocysteate in slices of rat cerebellar hemispheres and vermis. J Neurochem 1990; 54: 1533-1540.

14. Fonnum F. Glutamate: a neurotransmitter in mammalian brain. J Neurochem 1984; 42: 1-11.

15. Curtis DR, Watkins JC. The excitation and depression of spinal neurons by structurally related amino acids. J Neurochem 1960 ; 6: 117-141

16. Do KQ, Herrling PL, Streit $P$, et al. In virro release and electrophysiological effects in situ of homocysteic acid, an endogenous $\mathrm{N}$-methyl-(D)-aspartic acid agonist, in the mammalian striatum. J Neurosci 1986; 6: 2226-2234.

17. Do KQ, Mattenberger $M$, Streit $P$, et al. In vitro release of endogenous excitatory sulfur-containing amino acids from various rat brain regions. J Neurochem 1986; 46: 779-786.

18. Knöpfel T, Zeise ML, et al. L-homocysteic acid but not L-glutamate is an endogenous $N$-methyl-D-aspartic acid receptorpreferring agonist in rat neocortical neurons in vitro. Neurosci Lett 1987; 81: 188-192.

19. Provini L, Ito S, Ben Ari Y, et al. L-Homocysteate preferentially activates $N$-methyl-D-aspartate receptors to CAl rat hippocampal neurons. J Neurosci 1991; 3: 962-970.

20. Cuénod M, Do KQ, Grandes P, et al. Localization and release of homocysteic acid, an excitatory sulfur-containing amino acid. J Histochem Cytochem 1990; 38: 1713-1715.

21. Streit P, Grandes P, Morino P, et al. Immunohistochemical localization of glutamate and homocysteate. In: Meldrum BS, et al., eds. Excitatory Amino Acids. New York: Raven Press 1991; 61-67.

22. Somogyi P, Hodgson AJ, Smith AD, et al. Different populations of GABAergic neurons in the visual cortex and hippocampus of cat contain somatostatin- or cholecystokinin-immunoreactive material. J Neurosci 1984; 4: 2590-2603.

23. Zhang N, Ottersen OP. Differential distribution of two sulphur-containing amino acids in rat cerebellum: an immunocytochemical investigation using antisera to taurine and homocysteic acid. Exp Brain Res 1992; 90: 11-20.

24. Laake JH, Gundersen V, Nordbø G, et al. An antiserum against glutamine. In: Roberts PJ, et al., eds. Excitatory Amino Acids. London: Macmillan 1986; 448-450.

25. Zhang N, Laake J, Nagelhus E, et al. Distribution of glutamine-like immunoreactivity in the cerebellum of rat and baboon (Papio anubis) with reference to the issue of metabolic compartmentation. Anat Embryol 1991; 184: 213-223.

26. Ottersen OP, Storm-Mathisen J. Different neuronal localization of aspartate-like and glutamate-like immunoreactivities in the hippocampus of rat, guinea pig and Senegalese baboon (Papio papio) with a note on the distribution of GABA. Neuroscience $1985 ; 16: 589-606$.

27. Zhang N, Walberg F, Laake JH, et al. Aspartate-like and glutamatelike immunoreactivities in the inferior olive and climbing fiber system: a light microscopic and semiquantitative electron microscopic study in rat and baboon (Papio anubis). Neuroscience 1990; 38: 61-80.

28. Rinvik E, Ottersen OP. Demonstration of GABA and glutamate in the nucleus reticularis thalami: a postembedding immunogoldlabelling investigation in the cat and baboon. In: Bentivoglio $\mathrm{M}$, Spreafico R, eds. Cellular Thalamic Mechanisms. Amsterdam: Elsevier 1988; 321-337.

29. Ottersen OP, Zhang N, Walberg F. Metabolic compartmentation of glutamate and glutamine: morphological evidence obtained by quantitative immunocytochemistry in rat cerebellum. Neuroscience 1991; 46: 519-534. 
30. Wang B-L, Larsson L-I. Simultaneous demonstration of multiple antigens by indirect immunofluorescence or immunogold staining. Histochemistry 1985; 83: 47-56.

31. Blackstad TW, Karagülle T, Ottersen OP. MORFOREL, a computer program for two-dimensional analysis of micrographs of biological specimens, with emphasis on immunogold preparations. Comput Biol Med 1990; 20: 15-34.

32. Ottersen OP. Quantitative assessment of taurine-like immunoreactivity in different cell types and processes in rat cerebellum: an electronmicroscopic study based on a postembedding immunogold labelling procedure. Anat Embryol 1988; 178: 407-421.

33. Ottersen OP, Laake JH. Light and electron microscopic immunocytochemistry of putative neurotransmitter amino acids in the cerebellum with a note on the distribution of glutamine. $I n$ : Llinás $\mathrm{R}$,
Sotelo C, eds. The Cerebellum Revisited. New York: Springer 1992; 116-134.

34. Ottersen OP. Postembedding light and electron microscopic immunocytochemistry of amino acids: description of a new model system allowing identical conditions for specificity testing and tissue processing. Exp Brain Res 1987; 69: 167-174.

35. Bramham CR, Torp $R$, Zhang $N$, et al. Distribution of glutamatelike immunoreactivity in excitatory hippocampal pathways: a semiquantitative electron microscopic study in rats. Neuroscience 1990; 39: 405-417.

36. Bishop GA. Neuromodulatory effects of corticotropin releasing factor on cerebellar Purkinje cells: an in vivo study in the cat. Neuroscience 1990; 39: 251-257. 